\title{
Primary structure of two sialylated triantennary glycans from human serotransferrin
}

\author{
Geneviève Spik, Véronique Debruyne, Jean Montreuil, Herman van Halbeek ${ }^{+}$and \\ Johannes F.G. Vliegenthart ${ }^{+}$

\begin{abstract}
Laboratoire de Chimie Biologique et Laboratoire Associé au CNRS n. 217, Université des Sciences et Techniques de Lille I, F-59655 Villeneuve d' Ascq Cédex, France and 'Department of Bio-Organic Chemistry, University of Utrecht,
\end{abstract} \\ Croesestraat 79, NL-3522 AD Utrecht, The Netherlands
}

Received 4 January 1985; revised version received 15 February 1985

\begin{abstract}
Glycopeptides obtained from human serotransferrin by pronase digestion were separated into two fractions by affinity chromatography on Con A-Sepharose. The retarded fraction ( $85 \%$ of total glycopeptides) contained sialylated biantennary glycans of the $N$-acetyllactosaminic type, the primary structure of which has been previously determined. The non-retained fraction ( $15 \%$ of total glycopeptides) consisted of two isomeric triantennary glycans of the $N$-acetyllactosaminic type. The primary structure have been elucidated by methylation analysis and $500 \mathrm{MHz}{ }^{1} \mathrm{H}-\mathrm{NMR}$ spectroscopy. Both contain an additional $\operatorname{NeuAc}(\alpha 2 \rightarrow 3) \mathrm{Gal}(\beta 1 \rightarrow 4) \mathrm{GlcNAc}$ antenna. The latter is linked to C-4 of the $(\alpha 1 \rightarrow 3)$ bound Man residue in $45 \%$ of the glycans in the non-retained fraction but to C-6 of the $(\alpha 1 \rightarrow 6)$ bound Man residue, in the remaining $55 \%$ of the glycans in this fraction.
\end{abstract}

Transferrin NMR analysis Glycan structure Glycoprotein heterogeneity

\section{INTRODUCTION}

The structure of the $N$-glycosidically linked biantennary glycans of human serotransferrin has been described $[1,2]$. Heterogeneity of the serotransferrin glycans was discovered by Spik et al. [3] who isolated by free-flow electrophoresis two types of glycopeptides with a different molar carbohydrate composition. In addition, on the basis of methylation analysis, the presence of two types of triantennary glycans differing in their branching pattern was suggested by Krusius and Finne [4]. The structure of one type of triantennary asialoglycan has been proposed by März et al. [5].

Abbreviations: Con A, concanavalin A; Gal, Dgalactose; Man, D-mannose; GlcNAc, $N$-acetyl-Dglucosamine; NeuAc, $N$-acetylneuraminic acid; Asn, L-asparagine
Here, we describe the primary structure of two sialylated triantennary glycans occurring in human serotransferrin as determined by methylation analysis and $500 \mathrm{MHz}{ }^{1} \mathrm{H}$-NMR spectroscopy.

\section{MATERIALS AND METHODS}

\subsection{Reagents}

Human serotransferrin was purchased from Behringwerke (Marburg, FRG). Pronase E (70000 PUK/g) was from Merck (Darmstadt). Con A-Sepharose was obtained from Pharmacia (Uppsala), methyl $\alpha$-D-glucopyranoside from Koch-Light (Colnbrook, England) and Bio-Gel P-6 (200-400 mesh) from Bio-Rad (Richmond, $\mathrm{CA}$ ). $\mathrm{D}_{2} \mathrm{O}$ was from Aldrich (Milwaukee, WI).

\subsection{Preparation of the sialoglycopeptides}

Human serotransferrin was submitted to pronase digestion [6]. The resulting glycopeptides 
were purified by gel filtration on a Bio-Gel P-6 column $(2 \times 120 \mathrm{~cm})$ and then fractionated on a . Con A-Sepharose column $(2 \times 80 \mathrm{~cm})$ equilibrated in $5 \mathrm{mM}$ sodium acetate buffer, $\mathrm{pH} 5.2$, containing $1 \mathrm{mM} \mathrm{CaCl}, 1 \mathrm{mM} \mathrm{MgCl} 2$ and $1 \mathrm{mM} \mathrm{MnCl}$. Elution was carried out first with the above buffer containing $0.1 \mathrm{M} \mathrm{NaCl}$ and then with $15 \mathrm{mM}$ methyl $\alpha$-D-glucopyranoside [4].

\subsection{Analytical methods}

The molar carbohydrate composition of the glycopeptide fractions was determined by gasliquid chromatography after methanolysis and trifluoroacetylation [7]. For methylation analysis the glycopeptides were methylated according to Finne et al. [8], methanolysed and peracetylated [9]. The partially methylated methyl glycosides were identified and determined by gas-liquid chromatography in combination with mass spectrometry. Detection was carried out by measuring total ionization current as well as mass fragmentography (mass spectrometer RIBERMAG R 10-10 coupled to the data system SYDAR 121) [10]. For ${ }^{1} \mathrm{H}-\mathrm{NMR}$ spectroscopic analysis, the neutralized glycopeptides were repeatedly exchanged in $\mathrm{D}_{2} \mathrm{O}$ at room temperature with intermediate lyophilization. The $500 \mathrm{MHz}{ }^{1} \mathrm{H}-\mathrm{NMR}$ spectra were recorded on a Bruker WM-500 spectrometer (SON hf-NMR facility, Department of Biophysics, Nijmegen University, The Netherlands) operating in the Fourier transform mode and equipped with an Aspect-2000 computer [11]. Chemical shifts $(\delta)$ are expressed in ppm downfield from internal sodium 4,4-dimethyl-4-silapentane1-sulfonate, but were actually measured by reference to internal acetone $\left(\delta=2.225\right.$ in $\mathrm{D}_{2} \mathrm{O}$ at $27^{\circ} \mathrm{C}$ ).

\section{RESULTS}

The mixture of glycopeptides obtained from human serotransferrin by pronase digestion was separated into 2 fractions by chromatography on Con A-Sepharose columns. Fraction I eluted with the starting buffer containing $0.1 \mathrm{M} \mathrm{NaCl}$ represented $15 \%$ of the total amount of glycopeptides. Fraction II $(\mathbf{8 5 \%})$ retained by the lectin was eluted with $15 \mathrm{mM}$ methyl- $\alpha$-D-glucopyranoside. The molar carbohydrate composition of each fraction is given in table 1. The glycans of fraction II were identified as the sialylated biantennae of the $N$-acetyllactosamine type previously described [1] and were not further investigated. Methylation analysis of fraction $I$ led to the identification and determination of methyl derivatives listed in table 2 . The presence of 2,3,4,6-tetra- $O$-methyl galactoside $(0.4 \mathrm{~mol} / \mathrm{mol})$ shows that some galactose residues have been desialylated during freezedrying, after NMR analysis. The occurrence of 2,3,4-tri- $O$-methyl and 2,4,6-tri- $O$-methyl galactoside residues in the ratio of 1.7:1.1 indicates that in the completely sialylated glycan two galactose residues are substituted at $\mathrm{C}-6$ while the third one is substituted at $\mathrm{C}-3$. Identification of 3,6-di-Omethyl and 3,4-di- $O$-methyl mannoside, in addition to 2,4-di-O-methyl mannoside in the ratio of $0.45: 0.55: 1.0$, is interpreted in terms of the presence of two different types of triantennary glycans.

To elucidate unambiguously the primary structure of the two sialylated triantennary glycopeptides obtained from human serotransferrin, fraction I was analysed by $500 \mathrm{MHz}{ }^{1} \mathrm{H}-\mathrm{NMR}$ spectroscopy. In table 3 , the chemical shifts of the structural-reporter group protons of the two triantennary glycans are compared to those for similar triantennary glycopeptides and oligosaccharides isolated from various sources [11]. Crucial features have been indicated in italics. Glycopeptide STF- $A$ possesses a triantennary structure with an addition $(\alpha 2 \rightarrow 3)$-sialylated $N$ acetyllactosamine antenna $\beta-1,4$ linked to Man-4 (fig.1). This is evident from the set of chemical shift values of the Man $\mathrm{H}-1$ and $\mathrm{H}-2$ signals [11]. Glycopeptide STF- $B$ is a so-called $\operatorname{tri}^{\prime}$-antennary glycan [12] having the additional $(\alpha 2 \rightarrow 3)$ sialylated $N$-acetyllactosamine unit $(\beta 1 \rightarrow 6)$-linked to Man-4'. This can be deduced from the chemical shift of H-1 of Man- $4^{\prime}(\delta=4.862)$ in combination with the typical pattern of Man H-2 signals: Man-3, -4 and $-4^{\prime} \mathrm{H}-2$ at $\delta 4.25, \delta 4.20$ and $\delta 4.10$, respectively (table 3). This set of Man $\mathrm{H}-1$ and $\mathrm{H}-2$ chemical shift values is known to be highly indicative of the tri'-antennary branching pattern $[11,12]$.

The type of linkage, as well as the antenna location of the NeuAc residues present could be readily inferred from the ${ }^{1} \mathrm{H}$-NMR data given in table 3 [11]. The chemical shifts of H-3ax and H-3eq of the NeuAc residues themselves, together with the 
Table 1

Molar carbohydrate composition ${ }^{\mathrm{a}}$ of the human serotransferrin glycopeptides separated on Con ASepharose

\begin{tabular}{lccc}
\hline $\begin{array}{l}\text { Mono- } \\
\text { saccharide }\end{array}$ & \multicolumn{3}{c}{ Molar carbohydrate composition } \\
\cline { 2 - 4 } & $\begin{array}{c}\text { Mixture of } \\
\text { glycopeptides } \\
\text { (starting } \\
\text { material) }\end{array}$ & $\begin{array}{c}\text { Fraction } \\
\text { I }\end{array}$ & $\begin{array}{c}\text { Fraction } \\
\text { II }\end{array}$ \\
\hline Gal & 2.4 & 3.0 & 2.0 \\
Man & 3.0 & 3.0 & 3.0 \\
GlcNAc & 4.7 & 5.2 & 3.7 \\
NeuAc & 2.4 & 2.9 & 1.9 \\
\hline
\end{tabular}

a Calculated on the basis of 3 mannose residues per mol glycopeptide

effects on the chemical shifts of the reporter groups of residues in the antennae, as compared to the asialo reference compounds, are consistent with an $(\alpha 2 \rightarrow 6)$-sialylation of Gal-6 and $6^{\prime}$ for
Table 2

Molar ratios ${ }^{\mathrm{a}}$ of the methylated methyl-glycosides present in the methanolysate of the permethylated glycopeptide Con-A fraction I from human serotransferrin

\begin{tabular}{lc}
\hline Methyl ethers & $\mathrm{mol} / \mathrm{mol}$ \\
\hline$(4,7,8,9) \mathrm{Me}_{4}-\mathrm{NeuAcMe}$ & 2.3 \\
$(2,3,4,6) \mathrm{Me}_{4}$-Gal & 0.4 \\
$(2,3,4) \mathrm{Me}_{3}$-Gal & 1.7 \\
$(2,4,6) \mathrm{Me}_{3}$-Gal & 1.1 \\
$(3,4,6) \mathrm{Me}_{3}$-Man & 0.9 \\
$(3,6) \mathrm{Me}_{2}$-Man & 0.45 \\
$(3,4) \mathrm{Me}_{2}$-Man & 0.55 \\
$(2,4) \mathrm{Me}_{2}$-Man & 1 \\
$(3,6) \mathrm{Me}_{2}$-GlcNAcMe & 3.6 \\
\hline
\end{tabular}

a Calculated on the basis of one residue of $(2,4) \mathrm{di}-\mathrm{O}$ methyl mannoside

glycopeptide STF- $A$ as well as for STF- $B$, while the Gal-8 residue in STF- $A$ and the Gal-8 ${ }^{\prime}$ residue in STF- $B$ bear NeuAc in $(\alpha 2 \rightarrow 3)$-linkage. The structure of the glycans of glycopeptides STF- $A$ and STF- $B$ is shown in fig. 1 .
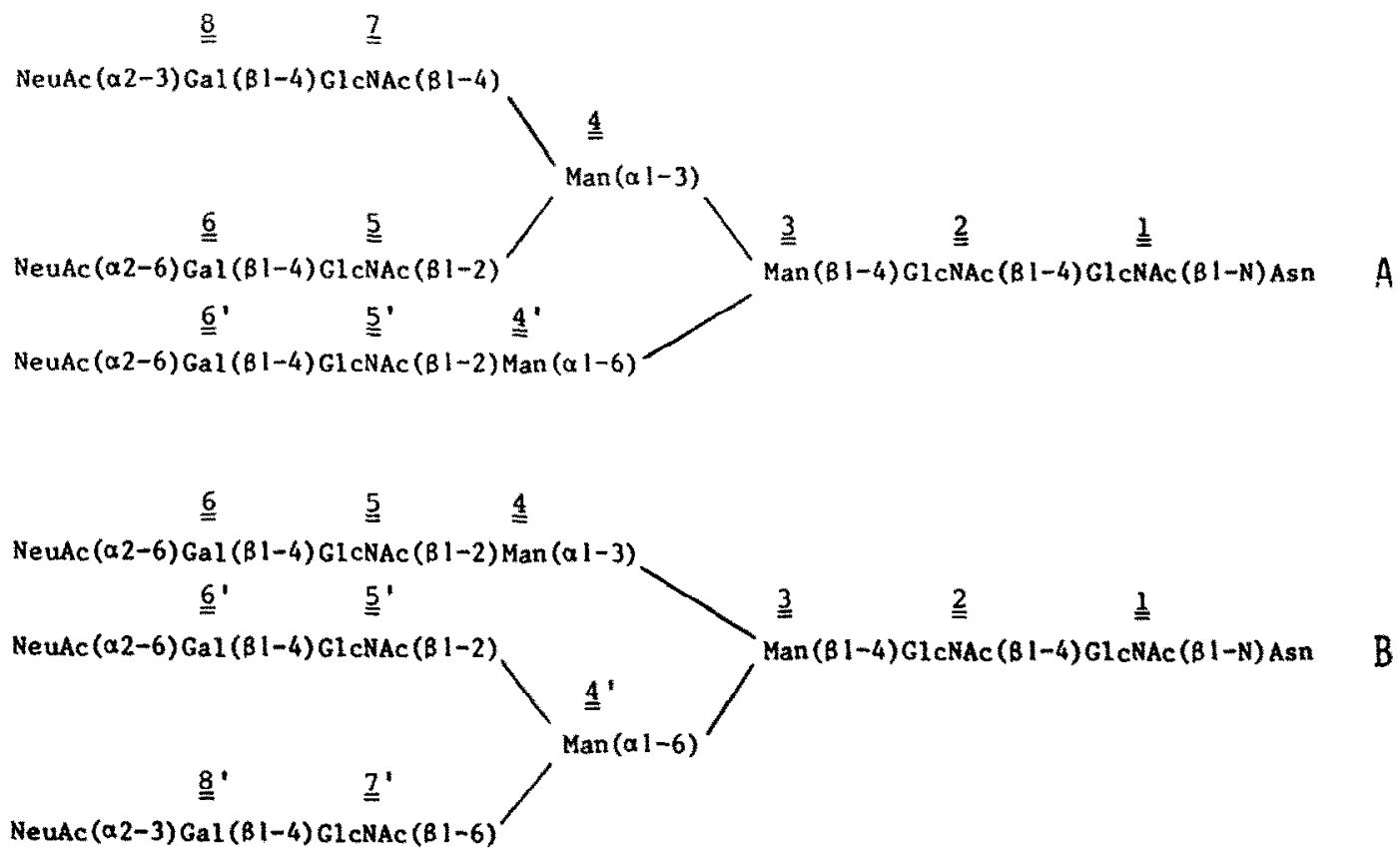

Fig.1. Primary structure of the two sialylated triantennary glycans from glycopeptides STF $A$ and STF- $B$ present in human serotransferrin Con $\mathrm{A}$ fraction $\mathrm{I}$. 
Table 3

${ }^{1} \mathrm{H}$ chemical shifts of structural-reporter groups of constituent monosaccharides for two tri-antennary glycans ( $A$ and $B$ ) occurring in human serotransferrin Con A fraction I, together with those for some reference compounds

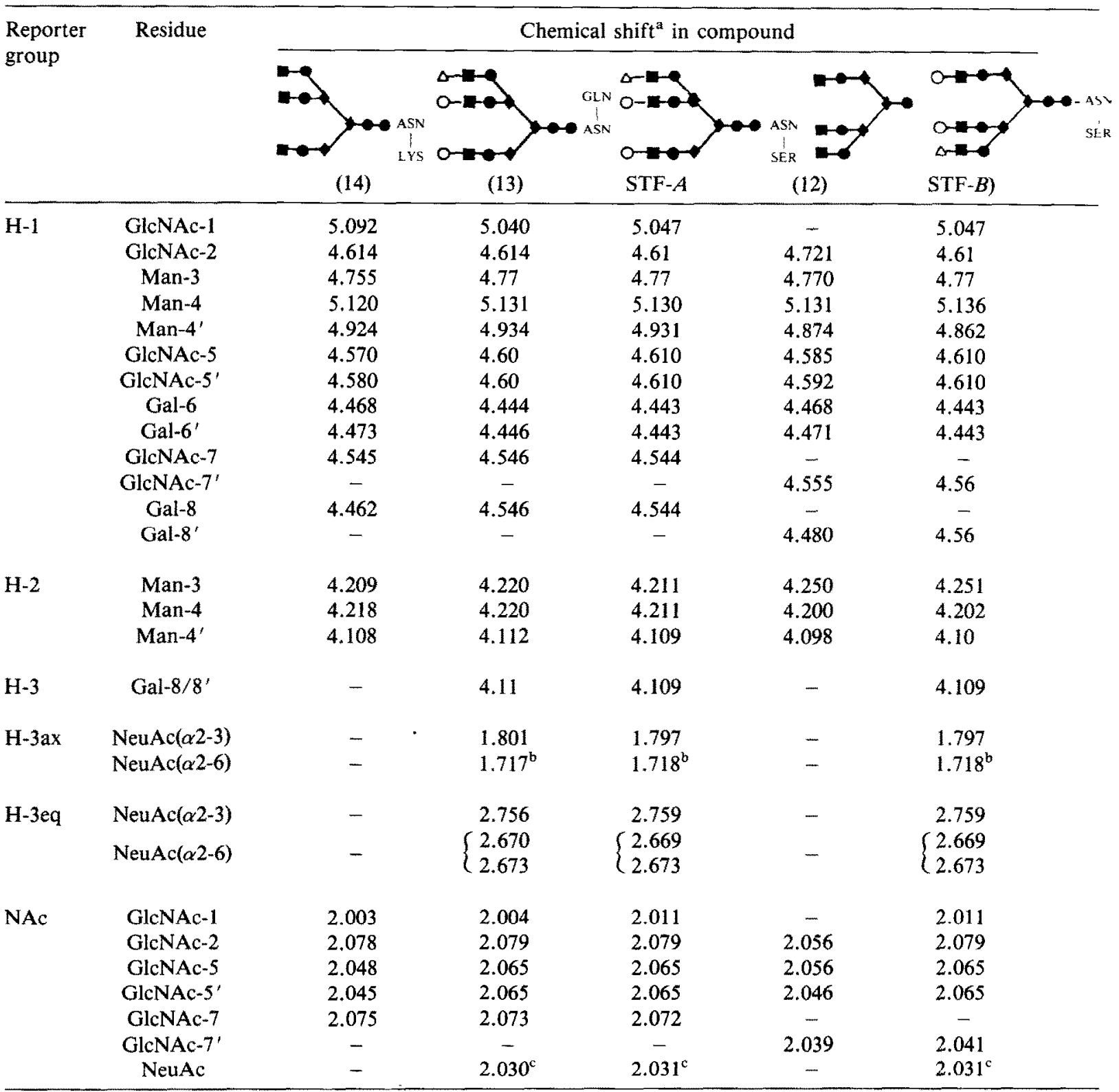

${ }^{\text {a }}$ Data were acquired at $500 \mathrm{MHz}$ for neutral solutions in $\mathrm{D}_{2} \mathrm{O}$ at $27^{\circ} \mathrm{C}$

b Signal stemming from 2 protons

c Signal stemming from 3 methyl groups

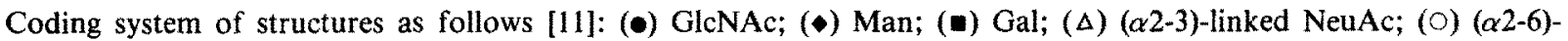
linked NeuAc 


\section{DISCUSSION}

The primary structure of the two sialylated triantennary glycans STF- $A$ and STF- $B$ present in human serotransferrin in the relative proportion of $45: 55$ has been described. The glycan of glycopeptide STF- $A$ appears to be identical to the major sialylated triantennary glycan from human plasma ceruloplasmin [13] and differs from the triantennary glycan of calf fetuin by the type of linkage of one $N$-acetylneuraminic acid residue [15]. The glycan of glycopeptide STF- $B$ was not characterized by ${ }^{1} \mathrm{H}-\mathrm{NMR}$ as such for any glycoprotein thus far. It differs from the tri'-antennary glycan characterized in porcine thyroglobulin [16] and in vesicular stomatitis virus membrane glycoprotein [17] by the linkages of the $N$-acetylneuraminic acid residues. It is noteworthy that the ${ }^{1} \mathrm{H}-\mathrm{NMR}$ spectrum of the mixture of glycopeptides obtained after exhaustive pronase digestion showed indications for the occurrence of small amounts of tetraantennary glycans.

The finding of two types of triantennary glycans in human serotransferrin is important with regard to the involvement of their desialylated analogues in the recognition process of asialotransferrin by the rat hepatic galactose-binding lectin [18]. In addition, we have observed an increase of the triantennary/biantennary glycan ratio in liver injury such as ethanol-induced liver cirrhosis [19]. The preliminary results we obtained in studying the hepatic uptake of ${ }^{59} \mathrm{Fe}$ from serotransferrin containing triantennary glycans, suggest that these structures could promote the development of hepatic siderosis observed in alcoholism [20].

\section{ACKNOWLEDGEMENTS}

This work was supported in part by the CNRS (Laboratoire Associé no. 217: Relations structurefonction des constituants membranaires), the Université des Sciences et Techniques de Lille I, the Fondation pour la Recherche Médicale, The Netherlands Foundation for Chemical Research (SON/ZNO) and grant UUKC 83-13 from the Netherlands Cancer Foundation (KWF).

\section{REFERENCES}

[1] Spik, G., Bayard, B., Fournet, B., Strecker, G., Bouquelet, S. and Montreuil, J. (1975) FEBS Lett. 50, 296-299.

[2] Dorland, L., Haverkamp, J., Schut, B.L. and Vliegenthart, J.F.G., Spik, G., Strecker, G., Fournet, B. and Montreuil, J. (1977) FEBS Lett. $77,15-20$.

[3] Spik, G., Vandersyppe, R., Fournet, B., Bayard, B., Charet, P., Bouquelet, S., Strecker, G. and Montreuil, J. (1974) Actes Colloq. Int. CNRS, no.221, CNRS, Paris, 483-500.

[4] Krusius, T. and Finne, J. (1981) Carbohydr. Res. 90, 203-214.

[5] März, L., Hatton, M.W.C., Berry, L.R. and Regoeczi, E. (1982) Can. J. Biochem. 60, 624-630.

[6] Spik, G. and Montreuil, J. (1969) Bull. Soc. Chim. Biol, 51, 1271-1285.

[7] Zanetta, J.P., Breckenridge, W.C. and Vincendon, G. (1972) J. Chromatogr. 69, 291-304.

[8] Finne, J., Krusius, T. and Rauvala, H. (1980) Carbohydr. Res. 80, 336-339.

[9] Fournet, B., Dhalluin, J.M., Strecker, G. and Montreuil, J. (1980) Anal. Biochem. 108, 35-56.

[10] Fournet, B., Strecker, G., Leroy, Y. and Montreuil, J. (1981) Anal. Biochem. 116, 489-502.

[11] Vliegenthart, J.F.G., Dorland, L. and Van Halbeek, H. (1983) Adv. Carbohydr. Chem. Biochem. 41, 209-374.

[12] Michalski, J.C., Strecker, G., Van Halbeek, H., Dorland, L. and Vliegenthart, J.F.G. (1982) Carbohydr. Res. 100, 351-363.

[13] Endo, M., Suzuki, K., Schmid, K., Fournet, B., Karamanos, Y., Montreuil, J., Dorland, L., Van Halbeek, H. and Vliegenthart, J.F.G. (1982) J. Biol. Chem. 257, 8755-8760.

[14] Van Halbeek, H., Dorland, L., Vliegenthart, J.F.G., Schmid, K., Montreuil, J., Fournet, B. and Hull, W.E. (1980) FEBS Lett. 114, 11-16.

[15] Nilsson, B., Norden E. and Svensson, S. (1979) J. Biol. Chem. 254, 4545-4553.

[16] Kondo, T., Fukuda, M. and Osawa, T. (1977) Carbohydr. Res. 58, 405-414.

[17] Stanley, P., Vivona, G. and Atkinson, P.H. (1984) Arch. Biochem. Biophys. 230, 363-374.

[18] Lee, Y.C., Townsend, R.R., Hardy, M.R., Lonngren, J., Arnarp, J., Haraldsson, M. and Lönn, H. (1983) J. Biol. Chem. 258, 199-202.

[19] Debruyne, V., Montreuil, J. and Spik, G. (1984) Prot. Biol. Fluids 31, 63-68.

[20] Spik, G., Mazurier, J., Legrand, D., Debruyne, V. and Montreuil, J. (1983) in: Structure and Function of Iron Storage and Transport Proteins (Urushizaki, I. et al. eds) pp.223-230, Elsevier, Amsterdam. 